\title{
How to bridge the gap between hospital and home?*
}

\author{
Diederik Kersten (social psychologist) \\ Research Fellow \\ and Ed Hackenitz (social geographer) \\ Research Fellow, Netherlands Institute of Primary Health Care, Utrecht, The Netherlands
}

Accepted for publication 1 June 1990

KERSTEN D \& HACKENITZ E (1991) Journal of Advanced Nursing 16, 4-14

\section{How to bridge the gap between hospital and home?}

Many countries have separate organizations for delivering nursing care to patients in the hospital and to patients at home in the community This separation creates extra difficulties in organizing continuous care for patients discharged from hospital who need nursing aftercare (in The Netherlands, at a rough estimate, $10 \%$ of all hospital patients) Special arrangements have to be made to prevent these patients missing out completely By means of a questionnaire sent to all Dutch regional community nursing organizations, this study makes an inventory of the organizational measures that have been taken in this field in The Netherlands and analyses a model of the effects these measures (and also the effects on contextual factors) have on the number of problems reported by the community in respect of continuity of care In The Netherlands, the initiative in arranging continuity of care is taken by the regional community nursing organizations or by their operational teams In most cases, they have been able to make arrangements with the hospitals about the selection of aftercare patients and the transfer of information by transfer forms Sometimes special continuity nurses are appointed by the community, among other things to organize regular consultation with the hospitals An eight-item Likert scale was developed to measure the extent of continuity problems Analysis of the effect of several factors in the model by a stepwise multiple regression analysis, revealed that the consistent use of transfer forms by hospitals was an important tool in reducing the problems Furthermore, regional community nursing organizations themselves had fewer problems compared with the operational teams to whom arranging continuity is sometımes delegated Increased personnel capacity within the community is also beneficial The effect of these last two factors (organizational level and personnel capacity) is, however, overruled, by the negative effect of the size of the regional community nursing organization the more inhabitants, the more problems there are

* Article based on a lecture given at the Intemational Conference on Community Nursing 16-17 March 1989 in s Hertogenbosch The Netherlands

Correspondence Mr D Kersten Research Fellow NIVEL (Netherlands Institute of Primary Health Care) PO Box 15683500 BN Utrecht The Netherlands

\section{INTRODUCTION}

In the seventies and early eighties there was a large number of English-language publications which developed the concept of continuity of care (Rogers \& Curtis 1980, 
Wall 1981, Bachrach 1981) The definitions given vary widely, depending on the point of view provider, patient, health care system In this article, we are concerned with contınuity of care as an organizational problem within a health care system The definition given by Shortell (1976) fits best 'continuity of care is the extent to which services are received as part of a coordinated and uninterrupted succession of events consistent with the medical needs of the patients' As we are concerned here with nursing care instead of medical care, we shall use this description for nursing care

Further, we shall focus on a specific aspect of nursing care, i e the patient's transition from hospital nursing care to community nursing care Many hospital patients need ongoing professional nursing care after their discharge In The Netherlands, the assumption is that this is the case for $10 \%$ of all discharged hospital patients (Nationale Ziekenhuisraad, Nationale Kruisvereniging 1978) In respect of continuity of care, the change from in-patient to out-patient nursing needs special attention in The Netherlands, as in many countries, different organizations are in charge The activities of hospital nurses end formally at the hospital door Of course, it is their professional responsibility to see that the patient is being cared for at home But they do not actually see the consequences of a too hasty or badly prepared hospital discharge Theoret1cally, hospital nurses might receive some feedback on this point from hospital readmission rates, but in fact the causes of readmission are complex Smith et al (1988) in particular were unable to show a positive relation between an intensive post-discharge care programme and a lower rate of hospital readmission

Community nurses, on the other hand, are dependent on others for timely information about the impending discharge of a patient who needs aftercare They are responsible for the delivery of nursing care at home, but they need to know when an aftercare patient is to be discharged Waiting for a signal from the patient will often mean several days of delay, assuming that the patient can find his way to the community nursing organization at all

What must be done to enable us to offer discharged hospital patients continuous care? First, it is important that in hospital the right patients are selected for post-discharge aftercare and also that these patients and their families need to be informed about all the aspects of the impending discharge Second, the information about the selected patients must arrive on time at the regional community nursing organization, so that the needs of the patient can be anticipated Third, it is necessary that the regional community nursing organization actually starts with adequate nursing help at home on time These three elements require structural arrangements with regard to aftercare to avoid contınuty problems The fact that problems do arise in selecting patients and transferring information in the Dutch situation is discussed elsewhere (Druver et al 1985, Verschuren 1987, Kersten 1988, Kersten 1988/1989) In the eyes of the community nurses, hospital nurses do not pay enough attention to psychosocial aspects of the need for aftercare And there are also complaints in the community about late notice of discharge Little is known in The Netherlands about the 'time gap' that occurs between hospital discharge and the start of the community nursing care

\section{Projects in The Netherlands}

Since the sixties, in The Netherlands there have been several local projects designed to develop organizational solutions to continuity problems For instance, in Amsterdam, in 1960, an independent aftercare service was established to select patients for aftercare and to transfer the information from the hospital to the community nursing teams in different districts of the city This service operated in a more or less similar way to the 'hospital at home' scheme in Peterborough, England (Clarke 1984), which again was inspired by the French 'hospitalisation à domicle' (Assistance Publıque, Hôpitaux de Parıs 1986) The main difference is that accelerating the discharge of patients was not an explicit goal in Amsterdam, but the organizational approach was more or less the same The Amsterdam aftercare service was closely related to the community nursing organizations Specialist nurses went into the hospitals to select the aftercare patients and to arrange the transfer of information to the community It should be noted that this transfer of information is a particularly difficult problem in Amsterdam, because there are as many as 13 hospitals in the city, each accepting patients from all over the city and even from outside it Furthermore, every community nursing team works more or less independently in a particular district This makes getting the information to the right community nurse who is eventually going to take care of the patient a complicated business

At present, there is no aftercare service in Amsterdam The main reason for this is that the benefits of the special aftercare service were no longer obvious Nurses from the aftercare service were seen as additional stations to pass on the road between the hospital nurses and the community nursing service (Schmitz 1985) There seems to be a simular tendency in the UK (Jowett \& Armitage 1988) Continuty of care in Amsterdam is now arranged by the hospital nursing teams and the community, using the infrastructure 
of the mutual contacts that have been bult up over the years

The project in Amsterdam, however, inspired many regional community nursing organizations in The Netherlands to start special contunuity of care programmes At first, aftercare services were initzated, but later on, less complex organizational solutions were started Regional community nursing organizations have put special 'continuity nurses' in charge so that there is consultation with the relevant hospitals about continuity of care, and structured steady arrangements about the way information about aftercare pahents is transfered to the community is also provided In 1979, in particular, funds were raised to appoint several of these contınuty nurses for penods of 2 years After these initiatives, the regional community nursing organizations in The Netherlands each went more or less their own way in respect of continuity of care Some found ways of continuing the appointment of continuity nurses, others made special efforts in order to provide organizational solutions for continuity problems without enlisting continuity nurses In these cases, the work was mostly done by the regular head community nurses

In this study, we are concerned with constructing an overview of the solutions the regional communty nursing organizations have developed to overcome the continuty problems In addition, we intend to analyse the effects of these solutions (and contextual factors) on the amount of problems that are expenenced with regard to contunuty of care in a specific area. In order to do this in a systematic way, an explanatory model was developed, presented in Figure 1

In the model, a distinction is made between hospitalbound factors, community-bound factors and both hospitaland community-bound factors Furthermore, a distunction is made between organizational factors that specifically have to do with the organization of the aftercare, and situational factors that have wider imphcations than exclusively the organization of aftercare The category, both hospital-and community-bound factors, is restricted to organizational factors, because the situational factors can exclusively be grouped under the categones hospital bound and community bound

We use the model in an explorative way For the vanables included, however, within a limited number of largely unambiguous steps in reasoning, it may be assumed that an effect can be hypothesized on the dependent vanable To keep it short, we will not detal all of the expected effects here. They are noted in the figure by pluses or minuses, clanfying the expected direction of the effect caused by the factor So, for instance, we expect more continuity problems from a greater number of hospitals transfernng after- care patients to the EKO/basic unit and, in contrast, a reduction of problems from the appointment of a cont1nuity nurse is expected On some of the varables presented in the model the reader will need explanation The comments are, however, to be found later on in the presentation of the descriptive results of this study

\section{RESEARCH QUESTION}

The decentralized way in which solutions to continuty problems have developed obstructs an overview of the situation On the one hand, there is no detaled overall picture of the way regional community nursing organizations attack the problems On the other hand, there are no clear views on the results these solutions provide, in terms of the amount of problems expenenced in the context of continuty of care

The prime question here is how the regional community nursing organizations provide structural solutions for problems of contunuty of care Second, we study how different solutions affect the number of problems expenenced in relation to continuity of care In order to answer this question, we will use the model presented in Figure 1

\section{Method}

All 185 regional communty nursing organizations (EKO, the abbreviation for Erkende Krus Organusatie) in The Netherlands were contacted. This action made clear that the EKO as a whole does not always organize aftercare after hospital discharge. 31 EKOs have passed over this responsibility to their executing teams, the basic units As a rule, a basic unit contains a head community nurse, 12 district nurses and about four nursing auxilianes

In order to get the necessary information, a questionnare was sent at the beginning of 1988 to 151 EKOs and 122 basic units (of 31 different EKOs), coverng all The Netherlands, with the exception of three EKOs that did not want to participate in the study 147 EKOs returned their questhonnaire (response percentage $97 \%$ ) and 87 basic units responded $(71 \%)$ The questionnaires were filled in by communuty officers with a key role in contunuty of care (head community nurse, contmuity nurse, etc)

In addition to questions about the general carcumstances of the EKO/basic unt (number of inhabitants in the working area, number of teaching and/or general hospitals that transfer patients for aftercare, etc) and the chosen solution for problems of contmuity of care (appointing a continuty nurse, organizing regular consultation with the hospitals 


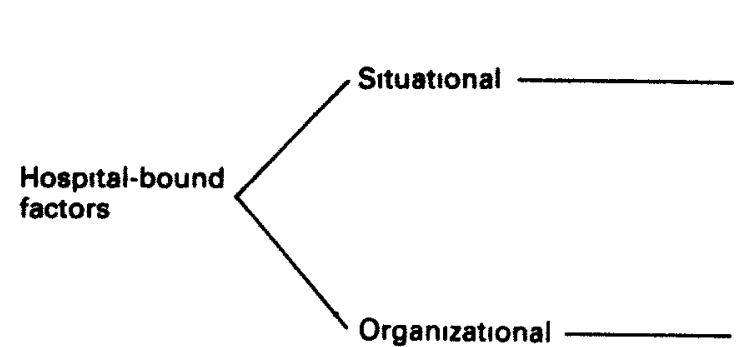

- Kınd of hospital general $(=1)$ or academic $(=0)$

$+1-$ Number of beds in hospital

$+1-$ Bed occupation percentage

- Average length of stay in hospital of all patients

Rate of use of transfer forms, distinction made between $34 \%$ * always $(=1)$ against the rest $(=0)$ $58 \%$ "'mostly $+7 \%$ " sometimes $+0 \%$ " never $+0 \%$ *



+ Personnel capacity *

$+\quad$ Number of inhabitants in the EKO area

$+\quad$ Percentage of people above 70 years of age in the EKO area

$+\quad$ Number of hospitals transferring aftercare patients to the EKO/basic unit

Amount of problems experienced in respect of contınuity of care

Both hospital- and community-bound factors
Appointment of continuity nurses, yes $(=1)$ or no $(=0)$

- Mutual co-operation between EKOs and/or basic units in regard to organizing continuity of care, yes $(=1)$ or no $(=0)$

+1 - Organizational level EKO $(=1)$ or basic unit $(=0)$ in charge of organızıng contınuity of care
- Appointment between EKO/basıc unit and hospital in regard to continuity of care, yes $(=1)$ or no $(=0)$

- Regular consultation between EKO/basic unit and hospital in regard to contınuity of care, yes $(=1)$ or no $(=0)$

Figure 1 Model to analyse the effects of organizational solutions in regard to continuty of care and also contextual effects on the amount of problems expenenced "The distribution for EKOs plus basic units for that specific hospital which transfers the biggest number of aftercare patients **Number of full-time community nurses and nursing auxilanes per 1000 inhabitants of 1-4 years of age and inhabitants above 60 years, this is proved to be the target population of the communty nursing organization (Hoeksma 1986) ***Expected direction of the effect by the factor $+=$ more problems, $-=$ less problems, $\pm=$ ambiguous

involved, etc), 10 statements (Likert items) were submitted to make an inventory of the problems expenenced with continuty of care. In addition to the literature, items were derived from open interviews with 15 hospital and community officers who have a key role in organizing continuty of care after hospital discharge Further information on the research method is to be found in an extensive study report (Zulmans \& Kersten 1989) Detalled information about the statistical techniques used can be found in Snedecor \& Cochran (1980) and Carmines \& Zeller (1985) 
Figure 2 Overview of the working areas of all 185 EKOs under study, with number of academic and general hospitals within the EKO borders $\bullet=1$ hospital. $O=2$ hospitals, $O=3$ hospitals, $=5-6$ hospitals, $\square=10-13$ hospitals



\section{RESULTS}

\section{General circumstances}

We will introduce our results with a map of the working areas of all EKOs in The Netherlands (Figure 2) The map shows first that there is an important (histoncally based) varnation in the size of the EKOs This is valid both for the size of the areas and the number of inhabitants There is a policy to bring groups of small EKOs together into one bigger EKO so that the total will decrease to about 60 (Nationale Kruisvereniging 1989)

Second, the map shows that some EKOs have to deal with a lot of hospitals The hospitals are concentrated in the bigger ches In most cases, one EKO receives aftercare patients from two, three or even more hospitals This is important because the community, in principal, has to make arrangements about transfernng aftercare patients with every single relevant hospital. Table 1 shows the actual distnbution based on the information from the 133 EKOs responding to this specific question and from the 87 basic units

As can be seen in Table 1 most EKOs and basic units receive aftercare patients from more than one hospital The average number of hospitals is 41 (standard deviation = 2.0) for the EKOs and 4.6 (standard deviation $=18$ ) for basic units So, although the workng area of a basic unit in general will be smaller when compared with a total EKO, we see that basic units even have to deal with a somewhat larger number of hospitals The reason is that the basic unitbased structure is found especially in more urban areas with a lot of hospitals

\section{Measures to solve continuity problems}

The first measure we shall discuss is the option of appointing a continuty nurse. In $64 \%$ of the EKOs and no more 
Table 1 Proportional distribution of EKOs (regional communty nursing organizations) and basic units to the number of hospitals from which they receive aftercare patients

\begin{tabular}{lcl}
\hline Number of hospitals & $\begin{array}{l}\text { EKOs } \\
(n=133) \\
\%\end{array}$ & $\begin{array}{l}\text { Basic units } \\
(n=87) \\
\%\end{array}$ \\
\hline 1 & 7 & 1 \\
2 & 20 & 10 \\
3 & 17 & 19 \\
4 & 17 & 21 \\
5 & 15 & 23 \\
6 & 13 & 10 \\
$7-10$ & 11 & 16 \\
& 100 & 100 \\
\hline
\end{tabular}

than $18 \%$ of the basic units, continuity nurses work parttume Together there are about 15 full-time posts The nurses' role is, in all cases, more or less the same promoting arrangements between hospitals and community on continuity of care (especially regarding the selection of aftercare patients and the transfer of information), coordinating regular consultations between community and hospitals, representing the community in these consultations, and promoting continuity of care within the community Almost none of the continuity nurses visit the hospitals to actually select aftercare patients themselves and to transfer the information So the position the continuity nurse had in the old aftercare service has virtually disappeared

Most probably in order to overcome the problems of the complex relation between hospitals and EKOs/basic units, most of the EKOs and basic units $(83 \%$ and $60 \%$ respectIvely) have decided to co-operate with each other in respect of contınuity of care Generally, a group of EKOs ( $53 \%$ of all EKOs) co-operates with the same continuity nurse basic unuts, generally ( $46 \%$ of all basic units), work together without having a joint continuty nurse They are mostly gearing their activities in the direction of the hospitals by regular consultation If there is a joint continuity nurse, she keeps in touch with the hospitals that are relevant for this group and tries to make similar arrangements about patient selection and information transfer with all of them, for all of the EKOs/basic units involved

Second, in order to evaluate and sometimes correct a situation, there must be regular consultation between both parties, 1 e hospitals and community $68 \%$ of all EKOs and $45 \%$ of all basic units have this knd of consultation with the hospitals which transfer aftercare patients to them. These consultations are held five times a year on average From the community, the head community nurses are generally present at the meetings, as are the continuty nurses (If there is one working for the EKO) The hospitals are most often represented by heads of the hospital departments or by a representative of the nursing division of the hospital

Third, it is important that, as a result of (former) consultations, there are regular arrangements about the selection of patients and the transfer of information $89 \%$ of the EKOs and $47 \%$ of the basic units report they have made these arrangements with the hospitals that are relevant to them Obviously, as far as EKOs are concerned, such arrangements are not always regularly evaluated in consultation meetıngs (compare $68 \%$ of the EKOs that have regular consultations with 'their' hospitals with $89 \%$ of the EKOs that report regular arrangements with 'their' hospitals) Arrangements are almost always for a complete hospital, not for single departments and, on the community side, they are mostly concerned with a group of EKOs and/or basic units

Finally, in order to have all the necessary information about aftercare patients, it is important that specially designed 'transfer forms' are used to transfer the information about aftercare patients from the hospital to the community The results show that $90 \%$ of the EKOs and $85 \%$ of the basic units generally (as they report 'always' or 'mostly') receive the necessary information by means of the special transfer forms

\section{Classification of the relationships between community and hospitals}

We have used the information presented above about the way EKOs/basic units solve problems of continuity of care after hospital discharge to make a classification of the relationships between hospitals and community The most distinct characteristics of such relationships are

1 there is or there is not a continuity nurse working within the relationship, and

2 there is either regular consultation or no regular consultation between both parties in the relationship (which also reveals something about the willingness of the hospital to co-operate)

The other charactenstics mentioned above hold in the same way for most hospital-community relationships at least as far as EKOs are concerned. The resulting classification is shown in Table 2

Statistical analysis of the figures in Table 2 reveals a significant difference between the cells (chi square $=298$, d.f $=1, P<0.01)$ Regular consultation is found most when 
Table 2 Classification of communty-hospital relations on the basis of the presence of a contunuty nurse on the one hand and regular consultation on the other (total number of communityhospital relations under study is 664)

Continuity nurse present

Yes No Totals

\begin{tabular}{|c|c|c|c|}
\hline \multicolumn{4}{|c|}{ Regular consultation } \\
\hline Yes & $32 \%$ & $27 \%$ & $59 \%$ \\
\hline No & $14 \%$ & $27 \%$ & $41 \%$ \\
\hline Totals & $46 \%$ & $54 \%$ & $100 \%$ \\
\hline
\end{tabular}

there is a continuty nurse active (32\%) Complementing this, we see that only $14 \%$ of the relations show no regular consultation where a continuty nurse is active So, at frrst sight the contınuty nurse's activities seem beneficial to regular consultation

In $27 \%$ of the relations between hospitals and community, there is regular consultation without the presence of a contınuity nurse These consultations will be organized by the regular head community nurses Finally, in $27 \%$ of the relations, there is nether regular consultation nor a continuity nurse Several interpretations of this result are possible, but the most likely seems to be that continuty of care is organized on the basis of appointments made in the past and/or that there is a rather weak organizational structure

\section{Problems with continuity of care in relation to different solutions and different context}

As we indicated before, 10 five-point Likert items were submitted to the respondents to list the problems expenenced with continuty of care Table 3 summanzes the answers given

The first five items in Table 3 concern continuity problems on the hospital side The respondents were able to give their opinion on the items for each hospital transferring aftercare patients to the EKO (or basic unit) separately The Table shows the opinion about the most important hospital, that is to say, the hospital that sends in the greatest number of patients Additionally, items 6 to 10 go into the problems on the community side

As we can see in Table 3, some problems are felt more than others On the hospital side, the motivation of the nursing staff to consult with the community about the transfer of aftercare patients (item 2) is seen as a (greater or smaller) problem by only $12 \%$ of the respondents The other items represent a problem for $33 \%$ to $47 \%$ of the respondents On the community side, the lack of public relations from the EKO/basic unit (item 7) and keeping up the necessary routine expenence with complicated nursing activities (item 9) are felt to be the major problems (by $46 \%$ and $52 \%$ respectively)

In order to obtain an overall indication of the continuity problems expenenced by each EKO/basic unit, a reliability analysis was made on the 10 items in Table 3 This revealed that items 1 to 8 constitute a scale with a standardized reliability coefficient, Cronbach's alpha, of $070 \mathrm{~A}$ sum score was therefore made by adding the individual scores on item 1 to 8 (mean score $=260$, standard deviation $=$ $556, n=182$ ), which is considered to measure the amount of problems expenenced in the field of continuity of care, with a higher score meaning fewer problems

We now analyse the explanatory model in Figure 1 This is done by a stepwise multiple regression analysis (MRA), testing the degree each of the factors in the model (while controlling for the effect of other factors) can explain differences in the amount of problems expenenced with regard to continuity of care Note that the model will be analysed for EKOs and basic units together because, despite the obvious differences, they are comparable with regard to organizing contınuity of care Furthermore, we are interested in possible differences between both organizational levels So the organizational level (EKO or basic units) is also included as an independent vanable in the model As 'organizational level' is a dichotomous vanable, it is scored in the 1 ( =EKO) against $\mathrm{O}$ (= basic unit) way It is the same for the other dichotomous variables in the model (compare Figure 1)

In prepaning the MRA, possible multicolinearity between the independent vanables was checked by inspecting the Pearson correlation coefficients The highest coefficient bound was 0.58 That is below the critical 070 value, so all the independent vanables were included in the MRA The completed MRA revealed that two factors in the model were included in the final equation, as is shown in Table 4

A constant use of transfer forms is beneficial in reducing the amount of problems with regard to continuity of care (a low sum score means a lot of problems) That is to say, if the respondent has reported in the questionnaire that a hospital 'always' uses transfer forms, signuficantly fewer problems are met, compared with the situation in hospitals that use transfer forms 'mostly' or 'sometimes'. The elasticity of the rate of use of transfer forms is +029 . which can be interpreted as follows: when hospitals always use transfer forms the amount of problems with regard 
Table 3 Percentual distnbution of the reactions to Likert items, representing problems experienced in relation to continuity of care ( $n$ respondents EKO/basic units $=210$ )

\begin{tabular}{|c|c|c|c|c|c|c|}
\hline Item & & $\begin{array}{l}\text { Totally } \\
\text { agree } \\
(=1) / \\
\text { agree }\end{array}$ & $\begin{array}{l}\text { Neither } \\
\text { agree nor } \\
\text { disagree }\end{array}$ & $\begin{array}{l}\text { Totally } \\
\text { disagree } \\
(=5) / \\
\text { disagree }\end{array}$ & $\begin{array}{l}\text { Mean } \\
\text { score }\end{array}$ & $\begin{array}{l}\text { Standard } \\
\text { deviation }\end{array}$ \\
\hline 1 & $\begin{array}{l}\text { The nurses in this hospital do not notice } \\
\text { the fact that some patients may need } \\
\text { psychosocial aftercare }\end{array}$ & 33 & 36 & 31 & 29 & 114 \\
\hline 2 & $\begin{array}{l}\text { The nursing staff in this hospital are little } \\
\text { motivated to consult with the community } \\
\text { about the transfer of aftercare patients }\end{array}$ & 12 & 15 & 73 & 39 & 112 \\
\hline 3 & $\begin{array}{l}\text { The nursing staff in this hospital tend to } \\
\text { organize aftercare for speafic groups of } \\
\text { patients (for instance with heart diseases) } \\
\text { themselves, instead of transferning these } \\
\text { patients to the community }\end{array}$ & 32 & 28 & 40 & 31 & 133 \\
\hline 4 & $\begin{array}{l}\text { This hospital is not inclined to transfer } \\
\text { aftercare patients who have had day } \\
\text { surgery }\end{array}$ & 47 & 22 & 31 & 28 & 135 \\
\hline 5 & $\begin{array}{l}\text { The nurses in this hospital do not know } \\
\text { enough about the help community nurses } \\
\text { are able to give }\end{array}$ & 43 & 26 & 31 & 28 & 118 \\
\hline 6 & $\begin{array}{l}\text { There are problems in having nursing aids } \\
\text { (objects) avalable for aftercare patients in } \\
\text { time }\end{array}$ & 19 & 27 & 54 & 35 & 110 \\
\hline 7 & $\begin{array}{l}\text { Your EKO/basic unit could do more to } \\
\text { inform the hospital nurses about the } \\
\text { nursing possibulities in the community }\end{array}$ & 46 & 24 & 30 & 28 & 130 \\
\hline 8 & $\begin{array}{l}\text { Community nurses and nursing auxilianes } \\
\text { in your EKO/basic unit are hard to contact } \\
\text { by telephone, if hospital nurses want to } \\
\text { consult them about aftercare patients }\end{array}$ & 17 & 18 & 65 & 38 & 128 \\
\hline 9 & $\begin{array}{l}\text { For the community nurses in your EKO/ } \\
\text { basic unit, it is difficult to keep up the } \\
\text { necessary routine expenence with regard } \\
\text { to complicated nursing activities }\end{array}$ & 52 & 21 & 27 & 26 & 137 \\
\hline 10 & $\begin{array}{l}\text { Aftercare patients that are transferred to } \\
\text { your EKO/basic unut often need more } \\
\text { nursing care than can be delivered }\end{array}$ & 10 & 17 & 74 & 40 & 108 \\
\hline
\end{tabular}

Table 4 Stepwise multiple regression analysis showing the significant effects $(P<0.005)$ of the factors in Figure 1 on the amount of problems expenenced in relation to aftercare $(n$ EKOs/basic units $=177$ )

\begin{tabular}{llll}
\hline & & & $R$ \\
Step & Factor & $\begin{array}{l}\boldsymbol{B} \\
\text { (elasticity) }\end{array}$ & $\begin{array}{l}\text { (explained } \\
\text { vanance) }\end{array}$ \\
\hline 1 & Rate of use of transfer forms & +0.29 & 0.08 \\
2 & Number of inhabitants in the EKO/basic unit area & -026 & 015 \\
\hline
\end{tabular}


to continuty of care declines by $29 \%(=0.29 \times 100 \%)$, compared to hospitals that use transfer forms less

Furthermore, the MRA reveals that the higher the number of inhabitants in the EKO (the bigger the EKO), the more problems are expenenced in regard to continuty of care The elasticity of the number of inhabitants is -026 . implying that an increase of, for instance, $20 \%$ in the number of inhabitants leads to a nse in the amount of problems with regard to continuty of care of $52 \%$ $(=026 \times 20 \%)$ Together, 'rate of use of transfer forms' and 'number of inhabitants' explain $15 \%$ of the vanance in the dependent vanable

Note that other factors in the model do not contribute significantly to the amount of explained vanance, after the effect of the factors in the first two steps is determined This also applies to the 'organizational level' factor (EKO versus basic unit) and the factor 'personnel capacity' The results of the MRA are, however, somewhat complicated in relation to these factors After the first step in the MRA, both these factors do indeed have a significant effect $(P<0.05)$ The effects are to be interpreted in the sense that a higher personnel capacity leads to fewer problems and, on the other hand, that an organization on EKO level leads to fewer problems These effects are, however, overruled in the second step, where the number of inhabitants of the EKO happens to be the factor that has the major effect The bivariate Pearson correlations can explain this The 'personnel capacity' appears rather strongly negatively related to the 'number of inhabitants of the EKO' (Pearson $r=$ $-054, P<00001)$ the bigger the EKO, the lower the personnel capacity It is the same for the organizational level, in that an organization on the basic unit level is found relatively more often in the bigger EKOs (Pearson $r=$ $-0.44, P<0.0001)$ So it will be clear that the effect of the 'number of inhabitants' on the one hand and the effects of 'personnel capacity' and 'organizational level' on the other hand operate on the dependent vanable in opposite ways And because the effect of the 'number of inhabitants' is the strongest in the second step of the MRA, the effects of the other two factors are overruled Therr impact, however, is important in the view of policy making

\section{DISCUSSION}

The results presented above give a description of the way the community nursing organization in The Netherlands has created an organizational structure intended to deliver contınuous nursing care after hospital discharge to patients Aftercare following hospital discharge is organized on a regional level by the regional community nursing organzation (EKO) or by its executing tearns (basic units) Despite the complex context, arising from the fact that one EKO/ basic unit in general has to deal with several hospitals (on average more than four hospitals) and vice versa, there seem to be basic conditions favounng continuity of care in most instances The solutions are based on a joint responsibility for continuity on both hospital and community nurses Hospital nurses select the patients for aftercare, prepare them for discharge, and transfer the necessary information to the community The EKOs - or in the case of 31 of the total number of 185 EKOs, the basic units - are, however, taking the initrative in making the necessary arrangements with the hospital staff regarding patient selection

Looking at the measures taken by the community, we see that in $64 \%$ of the EKOs, continuity nurses work parttime For the basic units in charge of organizing aftercare, this 1 no more than $18 \%$ The most probable reason seems to be that the choice of delegating the organization to basic units is part of a general policy to make the nurses in the community and the hospital on an executive level directly responsible for organizing aftercare Go-betweens like continuty nurses do not fit in well with this approach Probably the direct responsibility of the nurses on an executive level is also the reason that we see less regular consultation between basic units and 'their' hospitals (45\%) compared to EKOs and their hospitals (60\%) As a result, we find more often regular arrangements with hospitals about the selection of information and transfer of aftercare patients, when EKOs are responsible ( $89 \%$ for EKOs and $47 \%$ for basic units) In both the EKO hospital relations (hospital and the basic unit), transfer forms are generally used ( $90 \%$ and $85 \%$ respectively) to transfer the necessary information from hospital to community

A ch1-square analysis shows that the appointment of a continuity nurse does have a beneficial effect on the presence of regular consultation between EKO/basic unit and hospital about organizing aftercare it seems plausible to interpret this result in a causal way organizing regular consultation is the explicit task of the continuity nurse, so where there is such a nurse, we see this consultation more often We have to be careful, however, because both the presence of the continuity nurse and the consultation may be explained by the general favourable climate in the hospitals and EKOs towards continuity of care

\section{Continuity of care}

The results on the measured problems experienced in organizing continuity of care are very interesting We were able to make an eight-item scale to measure the amount of problems expenenced within an EKO or basic unit The 
scores on this scale were, in the first place, influenced by the rate of use of transfer forms Constant use decreases the amount of problems The rate of use of transfer forms is probably an expression of the extent to which the attitude in the hospital is favourable to continuity of care

We also saw that the more central approach of organizing contınuty at the EKO level diminishes the amount of problems This speaks against delegating too much to the executive level The background to the result is most likely that some involvement on a management level in the organization is necessary and, of course, this will be more easily achieved by an EKO, because there is more senior personnel

The bigger personnel capacity of EKOs was also beneficial in the avoidance of contınuity problems This may be in itself a rather trivial result, but in combination with the fact that bigger EKOs proved to have a relatively lower personnel capacity, it underlines the importance of a true balance in the distribution of the personnel

As we saw, both the effect of the organizational level and the personnel capacity are overruled by the effect of the number of EKO inhabitants Bigger EKOs have more problems and this cannot be explained by the greater number of hospitals they have to deal with This factor has been included in the model and showed no significant effect The result is a signal that the policy makers perhaps should be prudent in increasing the scale of the EKO areas, although this decision will be, of course, influenced by aspects other than continuity of care too

Finally, it is particularly striking that the MRA shows no effect from the appointment of a continuity nurse and from the regular consultation between hospitals and community on the amount of contınuity problems Obviously, these factors are presently less important than would be expected, as far as can be assessed by this study It is the same for the number of hospitals that transfer aftercare patients to one and the same EKO or basic unit The hypothesızed hampering effect of a greater number could not be shown

\section{Further research}

The current study was meant to make an inventory of the solutions to problems regarding continuity of care and to evaluate these solutions on the basis of the amount of problems expenenced on the community side The rate of use of transfer forms, the level on which continuity of care is organized in the community, the personnel capacity of the regional community organizations and the size of these organizations proved to be important factors that need special attention in policy making Further research could be aimed at the development of other measures for assessing continuity of care between hospital and community that take into account the patient's view Perhaps these studies would throw more light on the effectiveness of the appointment of continuity nurses which could not be shown in this study

\section{References}

Assistance Publique, Hôpitaux de Parıs (1986) Hospitalisation à domicile, rapport d'activité 1986 Assistance Publique Hôpitaux de Parns, 47 Boulevard de l'Hôpital, 75013, Parıs

Bachrach LL (1981) Continuity of care for chronic mental patients a conceptual analysis American Joumal of Psychiatry 138(11), 1449-1456

Carmines E G \& Zeller R A (1985) Reliability and Validtty Assessment A Sage University Paper no 17 (Sullıvan J L ed), Sage, Beverly Hills

Clarke F (1984) Hospttal at Home The Altemative to General Admission MacMillan, London

Drıver HF, van de Esch F , Kok G J \& Lako CJ (1985) (W $\left.W_{1 j k}\right)$ verpleegkundigen hanteren verschillende criteria bij nazorg Maatschappelijke Gezondherdszorg 10(1), 16-18

Hoeksma B H (1986) Grote tijdsinvestering in leeftudscategone $70+$ en jeugdgezondheidszorg Maatschappelijke Gezondherdszorg 14(1), 34-36

Jowett S \& Armitage S (1988) Hospital and community hasson links in nursing the role of the liaison nurse Joumal of Advanced Nursing 13, 579-587

Kersten T J J M T (1988) Home care after hospitalization In System Science in Health Care Health Care System and Actors (Duru $G$ ed), International Society for System Science in Health Care, Lyon, France, pp 723-726

Kersten TJJMT (1988/1989) Contınuiteitsproblemen in de zorgverlening Verpleegkunde 3(3), 125-133

Nationale Krusvereniging (1989) De Krutsorganisatie Nationale Krulsvereniging, Bunnik

Nationale Ziekenhussraad, Nationale Krusvereniging (1978) Aanbevelingen voor het tot Stand Komen van continuitet in de Verpleegkundige Zorg Natıonale Ziekenhuisraad, Nationale Krusverenuging, Utrecht

Rogers J \& Curtss P (1980) The concept and measurement of continuity in primary care American Joumal of Public Health 70, 122-127

Schmıtz L (1985) Kontınuitert in de Praktık De Bevruding, Amsterdam

Shortell SM (1976) Contınuity of medical care conceptualızation and measurement Medical Care 14, 377

Smith D M, Weinberger M, Katz B P \& Moore P S (1988) The cost-effectiveness of intensive postdischarge care a randomized trial Medical Care 26(11), 1092-1102

Snedecor G W \& Cochran W G (1980) Statistical Methods The Iowa State University Press, Ames, lowa 
Verschuren $M$ (1987) Nazorg we heeft het nodig? Tydschnft voor Ziekenverpleging 41(3), 69-72

Wall EM (1981) Continuty of care and family medicine definition, determmants, and relationships to outcome Family Practice 13(5), 655-664
Zjlmans WCM \& Kersten TJJMT (1989) Georgamiseerde Nazorg in Nederland (deel 2) Hoe is door het Kruswerk in Overleg met de Ziekenhuzen de Nazorg Georganuseerd? NIVEL. Utrecht 
This document is a scanned copy of a printed document. No warranty is given about the accuracy of the copy. Users should refer to the original published version of the material. 